\title{
The role of monetary policy uncertainty in predicting equity market volatility of the United Kingdom: Evidence from over 150 years of data
}

\author{
Rangan Gupta ${ }^{1} \cdot$ Mark E. Wohar $^{2,3, *}$ \\ ${ }^{1}$ Department of Economics, University of Pretoria, Pretoria, South Africa \\ ${ }^{2}$ College of Business Administration, University of Nebraska at Omaha, Omaha, NE, US \\ ${ }^{3}$ School of Business and Economics, Loughborough University, Leicestershire, UK
}

Received: 14 January 2019

Revised: 1 April 2019

Accepted: 3 April 2019

\begin{abstract}
Theory suggests a strong link between monetary policy rate uncertainty and equity return volatility, since asset pricing models assume the risk-free rate to be a key factor for equity prices. Given this, our paper uses historical monthly data for the United Kingdom over 1833:01 to 2018:07, to show that monetary policy uncertainty increases stock market volatility within sample, which in turn continues to hold under various robustness analyses. In addition, we show that the information on monetary policy uncertainty also adds value to forecasting out-ofsample equity market volatility.

Keywords: equity prices; monetary policy rate uncertainty; realized volatility; risk-free interest rates; volatility forecasting

JEL Classification Codes: C22, C52, E52, G12
\end{abstract}

\section{Introduction}

Poon and Granger (2003) point out that accurate prediction of volatility is of importance due to several reasons: Firstly, when volatility is interpreted as uncertainty, it becomes a key input to investment decisions and portfolio choices. Secondly, volatility is the most important variable in the pricing of derivative securities, with one needing reliable estimates of the volatility of the underlying assets to price an option. Thirdly, financial risk management according to the Basle Accord as established in 1996 also requires prediction of volatility as a compulsory input to risk-management for financial institutions around the world. Finally, financial market volatility, as witnessed during the recent global crisis, can have wide repercussions on the economy as a whole, via its effect on real economic activity and public confidence. Hence, estimates of market volatility can serve as a measure for the vulnerability of financial markets and the

\footnotetext{
* Corresponding author. E-mail: mwohar@unomaha.edu.

Citation: Gupta, R., and Wohar, M. (2019) The role of monetary policy uncertainty in predicting equity market volatility of the United Kingdom: Evidence from over 150 years of data, Economics and Business Letters, 8(3), 138-146.
}

DOI: $10.17811 / \mathrm{ebl} \cdot 8.3 .2019 .138-146$ 
economy, and can help policymakers design appropriate policies. Evidently, appropriate prediction of the process of volatility has ample implications for portfolio selection, the pricing of derivative securities and risk management (Rapach and Strauss, 2008). Not surprisingly, the literature on modelling and prediction of volatility is huge (see for example, Rapach et al., (2008), Babikir et al., (2012), Ben Nasr et al., (2014, 2016), Gil-Alana et al., (2014), and Yaya et al., (2015) for detailed reviews of this literature).

While volatility prediction has historically relied on univariate models, more recently, Engle and Rangel (2008), Rangel et al., (2011) and Engle et al. (2013), have highlighted the importance of financial and macroeconomic variables in capturing future movements in the volatility process of financial assets. In this context, Kaminska and Roberts-Sklar (2018) show that monetary policy rate uncertainty has important predictive power for equity return volatility over the last two decades for the Euro Area, the United Kingdom (UK) and the United States (US). As these authors theoretically point out, given that the monetary policy (i.e. short-term risk-free) rate is a key factor for pricing many securities and derivatives, there should be a strong link between monetary policy rate uncertainty and equity return volatility. This is understandable, since, according to basic present value models, the variance of equity prices is directly linked to the conditional variances of future discount rates, which are, in turn, the explicit functions of expected risk-free interest rates and risk premia. ${ }^{1}$ Against this backdrop, the objective of our analysis is to revisit the work of Kaminska and Roberts-Sklar (2018) over a monthly historical period of 1833:1 to 2018:7 for the UK. Such a long-span analysis avoids the issue pertaining to the sample-selection bias by capturing the longest possible evolution of the stock market and monetary policy, which in turn, also motivates the choice of the UK, given its data availability. For our purpose, we measure monetary policy uncertainty based on monthly realized volatility of the policy rate, since data is available at daily frequency, while stock return volatility is captured by fitting an appropriate model from Generalized Autoregressive Conditional Heteroskedasticity (GARCH) family, as stock prices data is obtainable only at monthly frequency over this period. To the best of our knowledge, this is the first attempt to relate stock market volatility in the UK with monetary policy uncertainty spanning over 150 years of historical data. The remainder of the paper is organized as follows: Section 2 discusses the data and methodology, while Section 3 presents the results, and Section 4 concludes.

\section{Data and methodology}

Our analysis involves two variables, which are measures of monetary policy uncertainty $(M P U)$ and stock returns volatility of the UK covering the period of January, 1833 to July, 2018, with the start and end dates being purely driven by data-availaility. Following, Kaminska and Roberts-Sklar (2018), MPU is measured by the monthly realized volatility of the daily monetary policy rate, ${ }^{2}$ i.e., sum of squared daily interest rates (covering $1^{\text {st }}$ January 1833 to $31^{\text {st }}$ July 2018) over the month (as suggested by Andersen and Bollerslev, (1998)). ${ }^{3}$ The daily interest rate data are derived from: A millennium of macroeconomic data, maintained by the Bank of England. ${ }^{4}$ Given the Zero Lower Bound (ZLB) situation in the UK in the wake of recent financial crisis, we replace the policy rate by the Shadow Short Rate (SSR) over the daily

\footnotetext{
${ }^{1}$ In this regard note that, Pástor and Veronesi (2012) have also theoretically related stock price movements with general government policy uncertainty.

${ }^{2}$ The daily policy rate was found to be stationary based on standard unit root tests. Complete details of these results are available upon request from the authors.

${ }^{3}$ We also estimated a $\operatorname{GARCH}(1,1)$ model for the interest rate variable at daily frequency, and then derived a measure of monthly realized volatility from the sum of the variance recovered from the model. Our main results reported in the paper continued to hold, and are available upon request from the authors.

${ }^{4}$ The data is available for download from: https://www.bankofengland.co.uk/statistics/research-datasets.
} 
period of 2009 until the end of the sample period. The SSR is the nominal interest rate that would prevail in the absence of its effective lower bound, with it derived by modelling the term structure of the yield curve. The SSR used in this paper is developed by Krippner $(2013)^{5}$, and it essentially removes the effect that the option to invest in physical currency (at an interest rate of zero) has on yield curves, resulting in a hypothetical "shadow yield curve" that would exist if physical currency were not available. The process allows one to answer the question: "what policy rate would generate the observed yield curve if the policy rate could be taken negative?" The "shadow policy rate" generated in this manner, therefore, provides a measure of the monetary policy stance after the actual policy rate reaches zero.

Our other variable of interest: stock market volatility is based on an univariate exponential GARCH (EGARCH) model fitted to log-returns $\left(r_{t}\right.$, i.e., the first difference of the natural logarithm of stock prices $\left(p_{t}\right)$, i.e., $r_{t}=\ln \left(p_{t}\right)-\ln \left(p_{t-1}\right){ }^{6}$ The corresponding FTSE All Share Stock Index (ALSI) data is obtained from the Global Financial Database (GFD). Note that, the choice of the EGARCH model over a family of other GARCH models was based on the ability of the former to better fit the data, in terms of standard goodness-of-fit measures. ${ }^{7}$ Note that, one empirical observation associated with equity markets is that, the impact of negative price moves on future volatility is different from that of positive ones, and the EGARCH model of Nelson (1991) captures this feature by its design of the volatility process. Formally, the EGARCH model used in this paper can be described as follows, by assuming the return process $\left(r_{t}\right)$ is given by:

$$
r_{t}=\mu+\sigma_{t} \varepsilon_{t}
$$

where, $\varepsilon_{t}$ is a sequence of $N(0,1)$ i.i.d. random variables, and

$$
\ln \left(\sigma_{t}^{2}\right)=\alpha_{0}+\frac{\alpha_{1} a_{t-1}+\gamma\left|a_{t-1}\right|}{\sigma_{t-1}}+\beta \ln \left(\sigma_{t-1}^{2}\right)+\theta M P U_{t-1}
$$

where $a_{t}=\sigma_{t} \varepsilon_{t}$. Notice that there is an asymmetric effect between positive and negative returns on volatility. Also, to avoid the possibility of a negative variance, the model is an $A R(1)$ on $\ln \left(\sigma_{t}^{2}\right)$ rather than $\sigma_{t}^{2}$. Understandably if $\theta$ is statistically significant in equation (2), then $M P U$ has predictive ability for the volatility of the FTSE ALSI of the UK. As indicated by Kaminska and Roberts-Sklar (2018), $\theta$ is expected to be positive, suggesting that $M P U$ increases equity market volatility.

Figure A1 in Appendix A plots the measure of MPU and the conditional variance derived from the EGARCH model, while Table A1 provides the summary statistics of these two variables of concern. Both the variables are found to have positive skewness and excess kurtosis, resulting in non-normal distribution as indicated by the overwhelming rejection of the null of normality under the Jarque-Bera test.

\footnotetext{
5 The data can be downloaded from the following link: https://www.rbnz.govt.nz/research-andpublications/research-programme/additional-research/measures-of-the-stance-of-united-states-monetarypolicy/comparison-of-international-monetary-policy-measures.

${ }^{6}$ The West and Cho (1995) modified Ljung-Box statistics, which are robust to conditional heteroskedasticity, provided no significant evidence of autocorrelation in the stock return. With respect to the squared return, the Ljung-Box statistics gave clear indication of serial correlation, and the Engle (1982) Lagrange multiplier statistic offer significant evidence of ARCH effects. Thus, these results provided support to modelling stock market volatility of returns in the UK using a GARCH process. Complete details of these results are available upon request from the authors.

${ }^{7}$ Complete details on the estimations of various symmetric and asymmetric GARCH models are available upon request from the authors.

${ }^{8}$ Note that, we did not include the lagged MPU term in the mean equation (1) of the model, since it was found to be associated with stock returns in a statistically insignificant manner (details of which are available upon request from the authors), besides the fact that, our focus here is on the relationship between uncertainty in monetary policy and volatility rather than returns.
} 


\section{Empirical results}

\subsection{Main results}

The estimation results for the EGARCH model are reported in Table 1. As can be seen, the coefficient on lagged MPU (i.e., $\theta$ ) is positive and statistically significant at the one percent level, suggesting that increases in uncertainty regarding monetary policy in the current period will result in increased volatility in the future. ${ }^{9}$ Given that we are considering a sample period that spans over 186 years of monthly data, it is very likely that the volatility process might have witnessed regime changes, i.e., structural breaks. Given this, we applied the Iterative Cumulative Sum of Squares (ICSS) algorithm also developed by Inclán and Tiao (1994) to detect multiple breaks in the unconditional variance, i.e., squared returns. The algorithm detected two breaks at 1868:02 and 1929:09. Figure A2 in Appendix A plots the stock returns series and three-standard-deviation bands defined by the structural breaks identified by the modified ICSS algorithm. In Table 1, we also report the EGARCH model estimations for the three-subsamples covering 1833:01-1868:01, 1868:02-1929:08, and 1929:09-2018:07. Again, as with the full sample, the estimate of $\theta$ is positive and statistically significant at the one percent level for sub-samples 2 and 3, and at the 5 percent level for the first sub-sample. In other words, the predictability of higher volatility due to $M P U$ is consistently observed for the stock market of the UK over time and across regimes.

Table 1. EGARCH Model Results.

\begin{tabular}{lccrr}
\hline \hline & \multicolumn{4}{c}{ Sample Periods } \\
\cline { 2 - 5 } Model Estimation & $\mathbf{1 8 3 3 : 0 1 -}$ & $\mathbf{1 8 3 3 : 0 1 -}$ & $\mathbf{1 8 6 8 : 0 2 -}$ & $\mathbf{1 9 2 9 : 0 9 -}$ \\
& $\mathbf{2 0 1 8 : 0 7}$ & $\mathbf{1 8 6 8 : 0 1}$ & $\mathbf{1 9 2 9 : 0 8}$ & $\mathbf{2 0 1 8 : 0 7}$ \\
\hline $\boldsymbol{\mu}$ & $0.0012^{* * * *}$ & 0.0014 & 0.0009 & $0.0052^{* * * *}$ \\
$\boldsymbol{\alpha}_{\boldsymbol{0}}$ & $-0.3994^{* * *}$ & $-0.4098^{* * *}$ & $-1.0465^{* * *}$ & $-0.9110^{* * * *}$ \\
$\boldsymbol{\alpha}_{1}$ & $0.2757^{* * *}$ & $0.2018^{* * *}$ & $0.2215^{* * *}$ & $0.2801^{* * * *}$ \\
$\gamma$ & $-0.0143^{* *}$ & 0.0216 & $0.0354^{*}$ & $-0.0804^{* * *}$ \\
$\boldsymbol{\beta}$ & $0.9750^{* * * *}$ & $0.9697^{* * * *}$ & $0.9013^{* * * *}$ & $0.8957^{* * * *}$ \\
$\boldsymbol{\theta}$ & $0.1375^{* * *}$ & $0.4269^{* *}$ & $1.3230^{* * * *}$ & $0.2890^{* * * *}$ \\
Log-Likelihood & 4843.8910 & 1009.1990 & 2024.8510 & 1849.686 \\
\hline \hline
\end{tabular}

Note. ${ }^{* * * *},{ }^{* *}$, and ${ }^{*}$ indicates significance at 1,5 and 10 percent levels respectively. The mean and volatility equations of the model are respectively: $r_{t}=\mu+\sigma_{t} \varepsilon_{t}$, and $\ln \left(\sigma_{t}^{2}\right)=\alpha_{0}+\frac{\alpha_{1} a_{t-1}+\gamma\left|a_{t-1}\right|}{\sigma_{t-1}}+\beta \ln \left(\sigma_{t-1}^{2}\right)+$ $\theta M P U_{t-1}$, where $M P U$ is the monetary policy uncertainty.

Given that in-sample predictability does not necessarily imply the same over an out-ofsample horizon, we formally conducted a forecasting exercise. Given that the first break date in the squared returns is derived at 1868:02, we estimate the EGARCH model with (unrestricted) and without (restricted) lagged $M P U$ over the in-sample period of 1833:01 to 1868:01, and then produced one-step-ahead out-of-sample forecasts over 1868:02 to 2018:07,

\footnotetext{
${ }^{9}$ Given that monthly data on stock returns and the policy rate is available from 1694:11 till 2018:07 (from the same sources discussed in the data segment), we created quarterly realized volatilities for both stock returns and the policy rate over 1694:4 to 2018:3. Again, the lagged uncertainty associated with the policy rate was found to be related in a positive and statistically significant manner (at the one percent level) with realized volatility of the stock market based on an ordinary least squares (OLS) regression. Finally, using the $k$-th order nonparametric causality-in-quantiles test developed by Balcilar et al., (2018), we observed that MPU predicted squared returns (i.e., unconditional variance) over the quantile range of 0.20 to 0.95 , i.e., barring the lower end of the conditional distribution of squared returns. The test statistic reached its maximum value at the moderately high quantile of 0.75. In other words, uncertainty of monetary policy is found to be strongly associated with larger volatility, but not so for smaller values of the same. Interestingly, based on this test, $M P U$ was found to predict returns too over its entire conditional distribution. Complete details of these results are available upon request from the authors.
} 
based on a recursive estimation. We then compared the forecast with the unconditional variance, i.e., squared returns. The obtained Relative Mean Square Forecast Error (RMSFE) from the MSFE of the unrestricted relative to the MSFE of the restricted model was 0.9956 $\left(=\left[3.1011 \times 10^{-5}\right] /\left[3.1147 \times 10^{-5}\right]\right)$, i.e., the model with lagged $M P U$ outperformed the model without it. The corresponding $M S E-F^{10}$ test statistic of McCracken (2007), appropriate for nested models, is found to be 7.9235, which is significant at the one percent level of significance. In other words, $M P U$ carries not only in-sample, but also out-of-sample predictive ability for the historical volatility of the stock market of the UK covering over 150 years of data.

\subsection{Robustness Analyses}

Based on the suggestion of two anonymous referee, we conducted five robustness analyses, with all these results reported in Table A2 of Appendix A of the paper. First, we included the lagged interest rate in the volatility equation. Second, we conducted the analysis at quarterly frequency following the works of Caggiano et al., (2014, 2017a, 2018), Pellegrino (2017) and Castelnuovo and Pellegrino (2018). Third, we included lagged measures of annual (consumer price index (CPI)) inflation and output (industrial production) growth $(\mathrm{GARCH}(1,1))$ volatility in the variance equation of the EGARCH model, with the period of analysis covering 1947:01 to 2018:07, given data availability. Fourth, we considered further sub-samples covering the post World War II data (1946:01-2018:07) and the post 1990 data (specifically, 1992:10 till 2018:07, with the start date corresponding to the start of the inflation targeting-regime of the Bank of England). Finally, in addition to lagged monetary policy uncertainty, we used a lagged interaction term between monetary policy and a dummy corresponding to 1 when the interest rate was less than equal to 3 percent and zero otherwise in the volatility equation. The value of 3 percent was derived from 1288 observations as per the classification-based summary statistic of the interest rate, and aims to capture the fact that when it comes to uncertainty the level of the interest rate is important (Caggiano et al., 2017b). As can be seen from Table A2, MPU continues to increase stock market volatility under the five robustness tests. In addition, we find that the level of interest rate increases stock market volatility, but the effect is significant only at the 10 percent level, and inflation and output volatility, though increases stock market volatility, has insignificant impact even at the 10 percent level of significance. We find that, the interaction term between $M P U$ and the dummy capturing low-levels (equal to or below 3 percent) of interest rate has a negative sign, suggesting that the monetary policy uncertainty at high interest rates (above 3 percent) is what causes an increase in stock market volatility.

\section{Conclusion}

It is expected that there should be a strong link between monetary policy rate uncertainty and equity return volatility, since asset pricing models assume the risk-free rate to be a key factor for equity prices. In this paper, using historical monthly data for the UK spanning 1833:01 to 2018:07, we test whether uncertainty about the future path of interest rates helps to predict future variance of equity returns. Consistent with theory, monetary policy rate uncertainty is positively and significantly related to uncertainty in equity markets within sample, with this result continuing to hold under various robustness analyses. Moreover, we show that the information on monetary policy uncertainty also adds value to forecasting equity market volatility over an out-of-sample period. These results suggest that views of investors on monetary policy rate developments may indeed be embedded in variation of equity prices. In

\footnotetext{
${ }^{10}$ Formally, the MSE-F test statistic is equal to: $(T-R-h+1) \times\left(M S F E_{0} / M S F E_{1}-1\right)$, where $M S F E_{0}\left(M S F E_{1}\right)$ is the $M S F E$ from the restricted (unrestricted) model, $T$ is the total sample size, $R$ is number of observations used for estimation of the model from which the first forecast is formed (i.e. the in-sample portion of the total number of observations), and $h$ the forecasting horizon. Note, in our case, $(T-R-h+1)$ is 1807 .
} 
addition, our analysis should be useful to practitioners and policymakers in their attempts to forecast near term volatility in the financial market of the UK. As part of future analysis, contingent on availability of long-span data especially for the monetary policy instrument at high (daily) frequency to compute realized volatility, our paper can be extended to analysing the role of monetary policy uncertainty in predicting long-span (historical) stock market volatility of other developed and emerging economies.

\section{Acknowledgments}

We would like to thank two anonymous referees for many helpful comments. However, any remaining errors are solely ours.

\section{References}

Andersen T. G., and Bollerslev T. (1998) Answering the skeptics: yes, standard volatility models do provide accurate forecasts, International Economic Review, 39(4), 885-905.

Babikir, A., Gupta, R., Mwabutwa, C., and Owusu-Sekyere, E. (2012) Structural Breaks and GARCH Models of Stock Return Volatility: The Case of South Africa, Economic Modelling, 29(6), 2435-2443.

Balcilar, M., Gupta R., Nguyen D. K., and Wohar, M. E. (2018) Causal effects of the United States and Japan on Pacific-Rim stock markets: nonparametric quantile causality approach, Applied Economics, 50(53), 5712-5727.

Ben Nasr, A. Ajmi, A. N., and Gupta, R. (2014) Modeling the Volatility of the Dow Jones Islamic Market World Index Using a Fractionally Integrated Time Varying GARCH (FITVGARCH) Model, Applied Financial Economics, 24(14), 993-1004.

Ben Nasr, A. Lux, T., Ajmi, A. N., and Gupta, R. (2016) Forecasting the volatility of the Dow Jones Islamic stock market index: Long memory vs. regime switching, International Review of Economics and Finance, 45(1), 559-571.

Caggiano, G., Castelnuovo, E., and Groshenny, N. (2014) Uncertainty Shocks and Unemployment Dynamics in U.S. Recessions, Journal of Monetary Economics, 67, 78-92.

Caggiano, G., Castelnuovo, E., and Nodari, G. (2017a) Uncertainty and Monetary Policy in Good and Bad Times, Melbourne Institute, Working Paper No. 9/17.

Caggiano, G., Castelnuovo, and Nodari, G. (2018) Risk Management-Driven Policy Rate Gap, Economics Letters, 171, 235-238.

Caggiano, G., Castelnuovo, E., and Pellergrino, G. (2017b) Estimating the real effects of uncertainty shocks at the Zero Lower Bound, European Economic Review, 110, 257-272.

Castelnuovo, E., and Pellegrino, G. (2018) Uncertainty-dependent Effects of Monetary Policy Shocks: A New Keynesian Interpretation, Journal of Economic Dynamics and Control, 93, 277-296.

Engle, R. F. (1982) Autoregressive conditional heteroskedasticity with estimates of U.K. inflation, Econometrica, 50, 987-1008.

Engle, R. F., and Rangel, J. G. (2008) The Spline-GARCH Model for Low-Frequency Volatility and Its Global Macroeconomic Causes, Review of Financial Studies, 21(3), 1187-1222.

Engle, R. F., Ghysels, E., and Sohn, B. (2013) Stock Market Volatility and Macroeconomic Fundamentals, Review of Economics and Statistics, 95(3), 776-797.

Gil-Alana, L. A., Shittu, O. I. and Yaya, O. S. (2014) On the persistence and volatility in European, American and Asian stocks bull and bear markets, Journal of International Money and Finance, 40(C), 149-162.

Inclán, C., and Tiao, C. G. (1994) Cumulative Squares for Retrospective detection of changes in Variance, Journal of the America Statistic Association, 89, 913-923. 
Kaminska, I., and Roberts-Sklar, M. (2018) Volatility in equity markets and monetary policy rate uncertainty, Journal of Empirical Finance, 45, 68-83.

Krippner, L. (2013) A Tractable Framework for Zero Lower Bound Gaussian Term Structure Models, Reserve Bank of New Zealand, Discussion Paper ref. 2013/02.

McCracken, W. (2007) Asymptotics for out of sample tests of Granger causality, Journal of Econometrics, 140, 719-752.

Pástor, L., and Veronesi, P. (2012) Uncertainty about government policy and stock prices, Journal of Finance, 67, 1219-1264.

Pellegrino, G. (2017) Uncertainty and Monetary Policy in the US: A Journey into NonLinear Territory, Melbourne Institute, Working paper no. 6/17.

Poon, S-H, and Granger, C. W. J. (2003) Forecasting Volatility in Financial Markets: A Review, Journal of Economic Literature, 41(2), 478-539.

Nelson, D. B. 1991. Conditional heteroskedasticity in asset returns: a new approach, Econometrica, 59, 347-370.

Rangel, J. G., and Engle, R. F. (2011) The Factor-Spline-GARCH Model for High and Low Frequency Correlations, Journal of Business \& Economic Statistics, 30(1), 109-124.

Rapach, D. E., and Strauss, J. K. (2008) Structural Breaks and GARCH Models of Exchange Rate Volatility, Journal of Applied Econometrics, 23(1), 65-90.

Rapach, D. E., Strauss, J. K., and Wohar, M. E. (2008) Forecasting stock return volatility in the presence of structural breaks, in Forecasting in the Presence of Structural Breaks and Model Uncertainty, David E. Rapach and Mark E. Wohar (Eds.), Vol. 3 of Frontiers of Economics and Globalization, Emerald, Bingley, United Kingdom, 381-416.

West, K. D., and Cho, D. (1995) The predictive ability of several models of exchange rate volatility, Journal of Econometrics, 69, 367-391.

Yaya, O. S., Gil-Alana, L. A., and Shittu, O. I. (2015) Fractional Integration and Asymmetric Volatility in European, American and Asian Bull and Bear Markets: Application to Highfrequency Stock Data, International Journal of Finance and Economics, 20(3), 276-290.

\section{Appendix A. Additional figures and tables.}

Figure A1. Data plot.

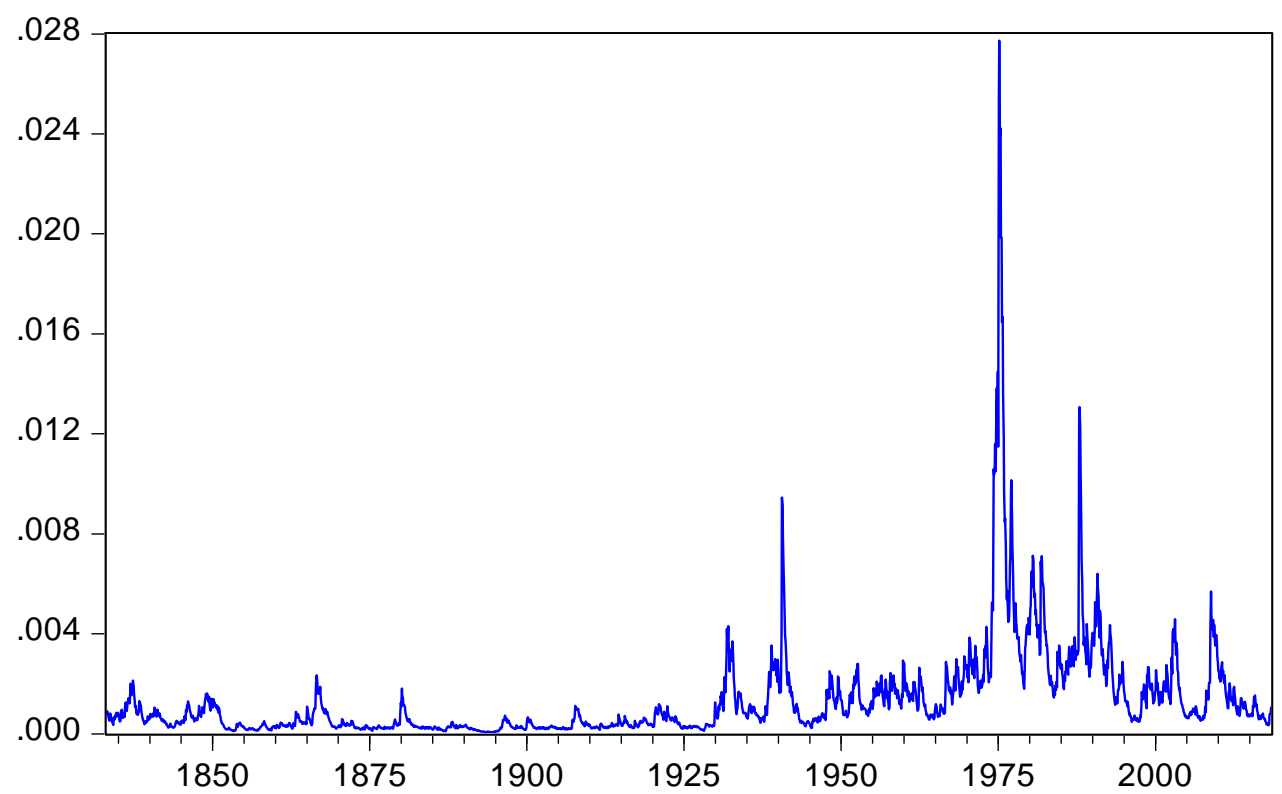

(a) Conditional Variance of Stock Market Returns of the UK from the EGARCH Model 


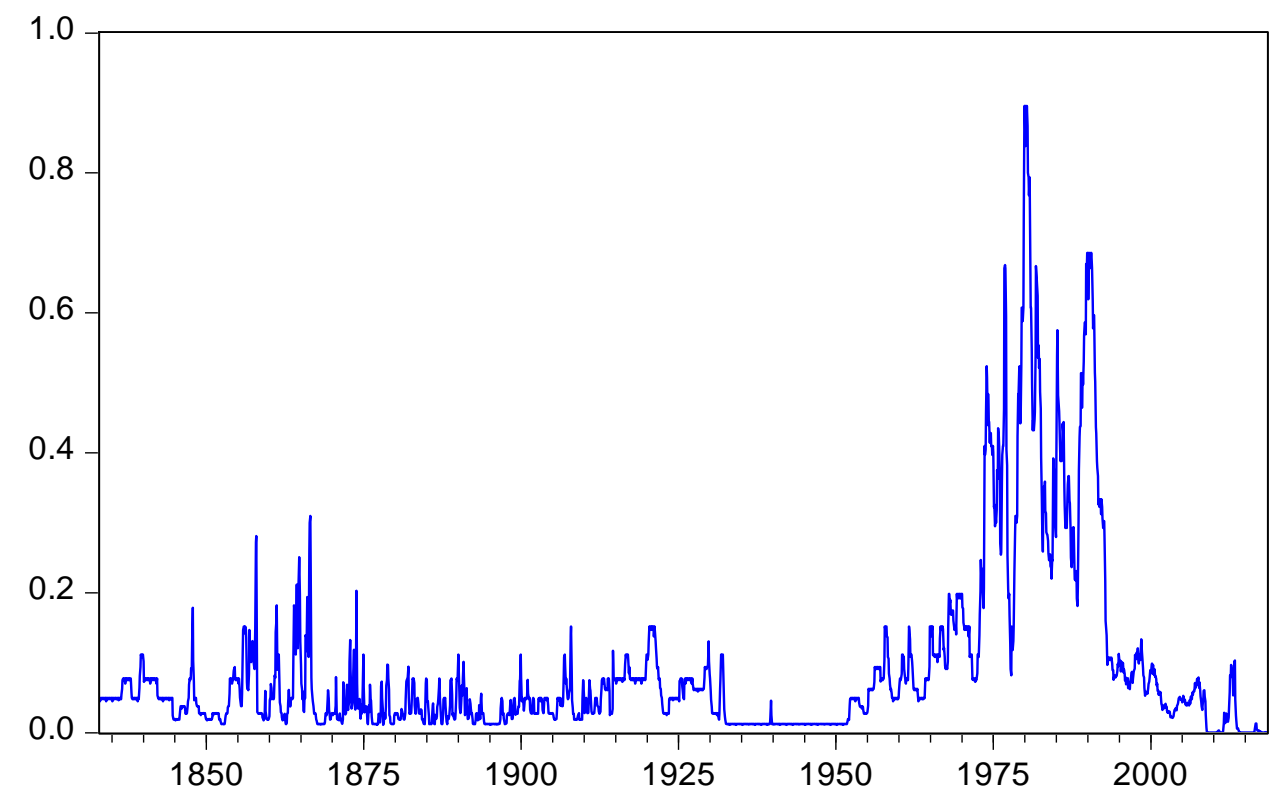

(b) Monthly Realized Volatility of the Monetary Policy Rate (MPU)

Figure A2. FTSE ALSI returns and \pm 3 standard deviation bands.

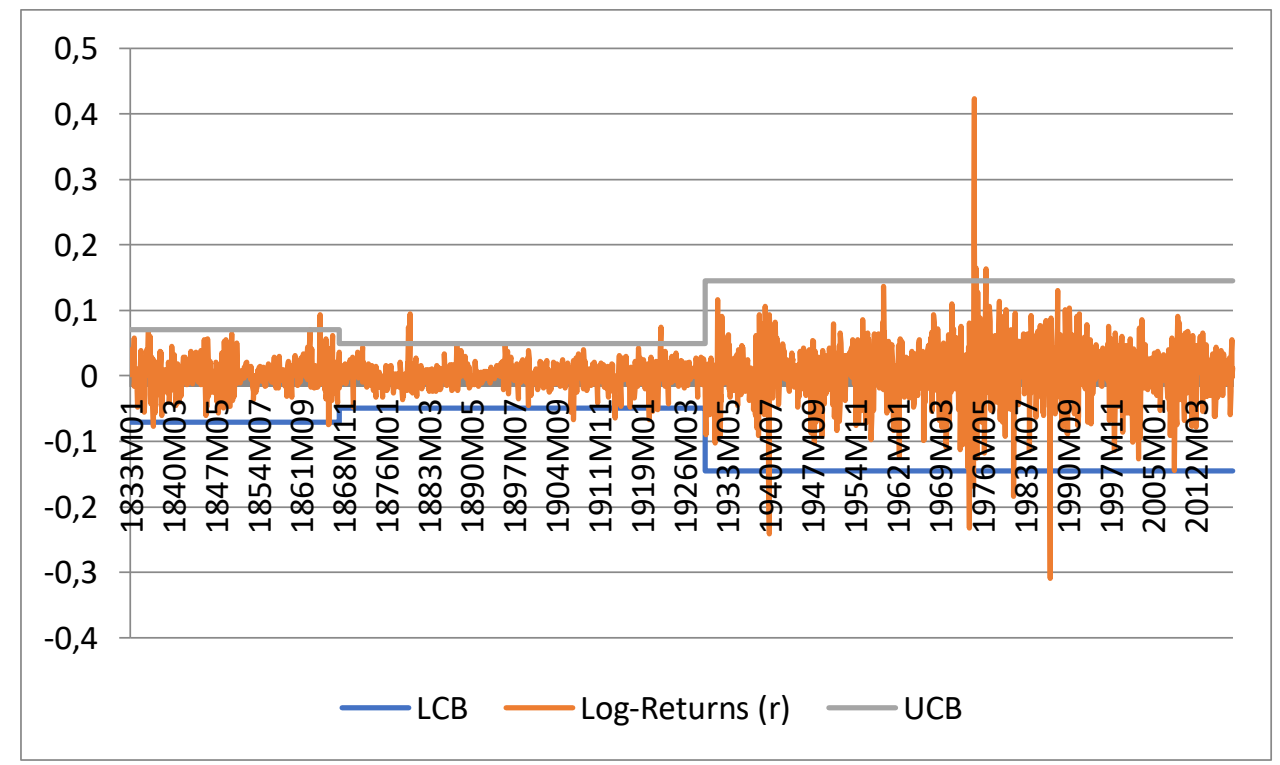

Note. LCB and UCB are lower and upper 3 standard deviation confidence bands.

Table A1. Summary statistics.

\begin{tabular}{lrr}
\hline \hline & \multicolumn{2}{c}{ Variable } \\
\cline { 2 - 3 } Statistic & $\begin{array}{r}\text { Conditional Volatility from } \\
\text { the EGARCH Model }\end{array}$ & MPU \\
\hline Mean & 13.5497 & 911.1759 \\
Median & 7.1762 & 496.0000 \\
Maximum & 277.2403 & 8959.0000 \\
Minimum & 0.5438 & 0.0356 \\
Std. Dev. & 20.3647 & 1319.8480 \\
Skewness & 5.6483 & 3.0376 \\
Kurtosis & 51.8856 & 13.1380
\end{tabular}




\begin{tabular}{lrr} 
Jarque-Bera & 233490.4000 & 12956.0500 \\
p-value & 0.0000 & 0.0000 \\
\hline Observations & & 2226 \\
\hline \hline
\end{tabular}

Note: Std. Dev. stands for standard deviation, while probability is the $\mathrm{p}-$ value for the Jarque-Bera test, with the null hypothesis of normality.

Table A2. EGARCH model robustness results.

\begin{tabular}{|c|c|c|c|c|c|c|}
\hline \multirow[b]{2}{*}{$\begin{array}{l}\text { Model } \\
\text { Estimation }\end{array}$} & \multicolumn{5}{|c|}{ Models } & \multirow[b]{2}{*}{$\begin{array}{l}\text { Model 6: } \\
\text { (1833:01- } \\
\text { 2018:07) }\end{array}$} \\
\hline & $\begin{array}{r}\text { Model 1: } \\
\text { (1833:01- } \\
\text { 2018:07 }\end{array}$ & $\begin{array}{c}\text { Model 2: } \\
\text { (1833:Q1- } \\
\text { 2018:Q3) }\end{array}$ & $\begin{array}{c}\text { Model 3: } \\
\text { (1947:01- } \\
\text { 2018:07) }\end{array}$ & $\begin{array}{l}\text { Model 4: } \\
\text { (1946:01- } \\
\text { 2018:07) }\end{array}$ & $\begin{array}{c}\text { Model 5: } \\
\text { (1992:10- } \\
\text { 2018:07) }\end{array}$ & \\
\hline$\mu$ & $0.0011^{* * *}$ & -0.0010 & $0.0055^{* * *}$ & $0.0058^{* * *}$ & $0.0055^{* *}$ & $0.0011^{* * *}$ \\
\hline$\alpha_{0}$ & $-0.4005^{* * *}$ & $-0.8249^{* * *}$ & $-0.9691^{* * *}$ & $-0.9125^{* * *}$ & $-1.0523^{* *}$ & $-0.3890^{* * * *}$ \\
\hline$\alpha_{1}$ & $0.2727^{* * *}$ & $0.3677^{* * *}$ & $0.2548^{* * *}$ & $0.2527^{* * * *}$ & $0.2451^{* *}$ & $0.2695^{* * *}$ \\
\hline$\gamma$ & -0.0134 & 0.0116 & $-0.0584^{* *}$ & $-0.0567^{* *}$ & $-0.1373^{* *}$ & -0.0140 \\
\hline$\beta$ & $0.9759^{* * *}$ & $0.9285^{* * *}$ & $0.8831^{* * *}$ & $0.8914^{* * * *}$ & $0.8789^{* * * *}$ & $0.9749^{* * *}$ \\
\hline$\theta_{1}$ & $0.1083^{* * *}$ & $12.5226^{* * * *}$ & $0.2791^{* * * *}$ & $0.2737^{* * * *}$ & $1.0091^{* *}$ & $0.1182^{* * * *}$ \\
\hline$\theta_{2}$ & $0.4175^{*}$ & - & - & - & - & - \\
\hline$\theta_{3}$ & - & - & 0.2990 & - & & - \\
\hline$\theta_{4}$ & - & - & 0.9409 & - & & - \\
\hline$\theta_{5}$ & - & - & - & - & - & $-0.7083^{* *}$ \\
\hline $\begin{array}{l}\text { Log- } \\
\text { Likelihood }\end{array}$ & 4844.8840 & 1612.5670 & 1451.9960 & 1483.0350 & 594.6293 & 4845.0250 \\
\hline
\end{tabular}

Note. ${ }^{* * *},{ }^{* *}$, and ${ }^{*}$ indicates significance at 1, 5 and 10 percent levels respectively. The mean and volatility equations of the model are respectively: $r_{t}=\mu+\sigma_{t} \varepsilon_{t}$, and $\ln \left(\sigma_{t}^{2}\right)=\alpha_{0}+\frac{\alpha_{1} a_{t-1}+\gamma\left|a_{t-1}\right|}{\sigma_{t-1}}+\beta \ln \left(\sigma_{t-1}^{2}\right)+$ $\theta_{1} M P U_{t-1}+\theta_{2} I N T_{t-1}+\theta_{3} I P G V O L_{t-1}+\theta_{4} C P I V O L_{t-1}+\theta_{5} M P U_{t-1} \times D_{t-1}$, where MPU, INT, IPGVOL and CPIVOL stands for the monetary policy uncertainty, interest rate, $\mathrm{GARCH}(1,1)$ model-based volatilities of annual industrial production growth and CPI inflation rate respectively, and $D$ is a dummy variable which takes a value of 1 for interest rate less than or equal to 3 percent. 